\title{
A Randomized Controlled Trial to Increase Cancer Screening Among Attendees of Community Health Centers
}

\author{
Richard G. Roetzheim, MD, MSPH ${ }^{1,2}$ \\ Lisa K. Christman, $B S^{1}$ \\ Paul B. Jacobsen, $\mathrm{PbD}^{2}$ \\ Alan B. Cantor, $P b D^{2}$ \\ Jennifer Scbroeder, BS ${ }^{1}$ \\ Rania Abdulla, $B S^{1}$ \\ Seft Hunter, $M A^{1}$ \\ Thomas N. Chirikos, $P b D^{2}$ \\ Jeffrey P. Krischer, $P b D^{2}$ \\ ${ }^{1}$ Department of Family Medicine, University \\ of South Florida, Tampa, Fla \\ ${ }^{2} \mathrm{H}$. Lee Moffitt Cancer Center \& Research \\ Institute, Tampa, Fla

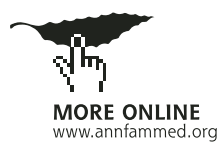

Conflicts of interest: none reported

\section{CORRESPONDING AUTHOR}

Richard Roetzheim, MD

Department of Family Medicine

University of South Florida

12901 Bruce B. Downs Blvd. MDC 13

Tampa, FL 33612

rroetzhe@hsc.usf.edu

\begin{abstract}
BACKGROUND We assessed the efficacy of the Cancer Screening Office Systems (Cancer SOS), an intervention designed to increase cancer screening in primary care settings serving disadvantaged populations.

METHODS Eight primary care clinics participating in a county-funded health insurance plan in Hillsborough County, Fla, agreed to take part in a cluster-randomized experimental trial. The Cancer SOS had 2 components: a cancer-screening checklist with chart stickers that indicated whether specific cancer-screening tests were due, ordered, or completed; and a division of office responsibilities to achieve high screening rates. Established patients were eligible if they were between the ages of 50 and 75 years and had no contraindication for screening. Data abstracted from charts of independent samples collected at baseline $(n=$ $1,196)$ and at a 12-month follow-up ( $n=1,237)$ was used to assess whether the patient was up-to-date on one or more of the following cancer-screening tests: mammogram, Papanicolaou (Pap) smear, or fecal occult blood testing (FOBT).
\end{abstract}

RESULTS In multivariate analysis that controlled for baseline screening rates, secular trends, and other patient and clinic characteristics, the intervention increased the odds of mammograms (odds ratio $[\mathrm{OR}]=1.62,95 \%$ confidence interval $[\mathrm{Cl}]$, $1.07-9.78, P=.023)$ and fecal occult blood tests $(\mathrm{OR}=2.5,95 \% \mathrm{Cl}, 1.65-4.0$, $P<.0001)$ with a trend toward greater use of Pap smears $(\mathrm{OR}=1.57,95 \% \mathrm{Cl}$, $0.92-2.64, P=.096)$.

CONCLUSIONS The Cancer SOS intervention significantly increased rates of cancer screening among primary care clinics serving disadvantaged populations. The Cancer SOS intervention is one option for providers or policy makers who wish to address cancer related health disparities.

Ann Fam Med 2004;2:294-300. DOI: 10.1370/afm.101.

\section{INTRODUCTION}

$\mathrm{P}$ atients belonging to a racial or ethnic minority are more likely to have poor cancer outcomes. ${ }^{1.7}$ Eliminating racial or ethnic disparities in health was a major emphasis of former Surgeon General Satcher and is now a public health goal for Healthy People 2010 (http://www.healthypeople.gov). Patients of low socioeconomic status and those who are uninsured or insured by Medicaid are also at greater risk of poor cancer outcomes. ${ }^{4,5,8-14}$ The reasons the aforementioned groups have less favorable cancer outcomes is not certain but have been largely attributed to lower use of screening tests. ${ }^{15-24}$

Interventions to increase cancer screening have been systematically reviewed, and several limitations relevant to cancer screening in primary care can be identified. ${ }^{25-29}$ First, many successful interventions have relied on computer systems and technology that may not be widely available to clinics caring for the underserved. ${ }^{30-46}$ Likewise, other successful interventions have relied on personnel and resources that would not typically be 
available to primary care practices, such as lay health advisors, telephone counselors, or nursing staff dedicated solely to cancer screening. ${ }^{47-54}$ Finally, whereas noncomputerized office systems interventions have been successful when targeted to typical primary care settings, ${ }^{33,55-57}$ their effectiveness in clinics serving disadvantaged populations is less certain, with some interventions having success ${ }^{58}$ and others not. ${ }^{59}$

To address these limitations, we developed a lowcost office systems intervention, Cancer Screening Office Systems (Cancer SOS), * for primary care clinics serving disadvantaged populations. The intervention is noncomputerized and relies on personnel and resources that are available to most primary care clinics. We tested the efficacy of the system among patients attending community health centers, a representative setting of care for the target population.

\section{METHODS}

To target an underserved population, clinics were recruited from among 16 clinics participating in a county-funded health insurance plan in Hillsborough County, Fla. The county health plan provides health care for uninsured persons who do not qualify for Medicaid or Medicare and who have a serious chronic health condition. Clinics were eligible for the randomized trial if (1) they provided primary medical care 5 days a week, (2) a majority of the physician and nonphysician providers agreed to participate, and (3) the clinic was expected to continue operating in the same fashion for the following 24 months. Each clinic individually decided whether to participate in the intervention; no clinic was obligated to join the intervention.

Eight clinics did not meet eligibility. One clinic refused to participate, 1 clinic was open only 1 day per week, and 6 clinics were uncertain whether they would be operating in the same fashion during the 2 year period of the grant (possibility of closing down, merging with another clinic, reducing days of service, loss of key personnel, etc). We performed a cluster-randomized experimental trial in which 8 clinics meeting eligibility criteria were randomized to either intervention or control conditions. Screening outcomes were assessed at 12 months and at 24 months. Results from 12 months of follow-up are reported here.

The intervention targeted 3 cancer-screening tests: mammograms, Papanicolaou (Pap) smears, and fecal occult blood tests (FOBT). Key components of the intervention included a cancer-screening checklist completed by patients and indicating whether patients were due for

* Cancer SOS materials and methods are freely available for use at the following Web site:http://www.hsc.usf.edu/FAMILY/research/index.htm. screening, and a series of red, yellow, and green stickers that indicated whether recommended screening tests had been ordered and completed. Appendix 1, which is available online only at http:/www.annfammed. org/cgi/content/full/2/4/294/DC1, provides additional detail about the clinics that participated and additional detail about the intervention itself.

Intervention procedures were explained to office staff and providers during a 45 -minute training session and were summarized in training manuals given to all staff. To insure that the Cancer SOS intervention was being implemented appropriately, project staff conducted unannounced audits of a random sample of 25 charts (of eligible patients seen in the most recent week) at 1 month, 2 months, and 3 months. Audits determined the percentage of eligible patients who appropriately had Cancer SOS checklists in their chart and whether the color-coded stickers were appropriately used. Compliance with the system was also assessed during formal feedback sessions with clinic staff that occurred every 6 months. Overall compliance with the system averaged $74 \%$ at 6 months and $71 \%$ at 12 -months. At these same times, project staff also assessed control clinics for possible contamination of intervention methods (which was not found).

To provide ongoing reinforcement of the intervention to clinic staff, we conducted formal feedback sessions at 6 months and at 12 months after the intervention had been implemented. A random sample of 50 charts was abstracted before the 6-month session to provide clinicians and staff with feedback on how their screening rates were progressing under the intervention. Office staff and project staff jointly discussed how the intervention was proceeding, what problems were occurring, and what might be done to improve implementation.

\section{Data Collection}

During data collection periods, research assistants assembled sampling frames of all patient visits using office billing and scheduling records. Patient's records were eligible to be abstracted if both the following criteria were met: (1) the patient was 50 to 75 years of age, and (2) the patient was established in the clinic (defined as having had at least 1 visit 12 months or more before the sampled visit). Based on sample size requirements for the intervention (the intervention was structured to provide $80 \%$ power to detect increases in screening rates of $20 \%$ or more), independent random samples of 150 charts were selected for each clinic at baseline and again 12 months after the intervention had been fully implemented in the clinic. Random selection was achieved using a list of random numbers generated by SAS/STAT software (SAS Institute, Inc, Cary, NC).

To prevent medical record reviews from influenc- 
ing patient or provider screening behavior, and to allow adequate time for recommended screening tests to be completed, we abstracted charts 3 months after sampled patients had visited the clinic. Neither patients nor staff members were aware of when chart abstractions would occur. In addition, randomization of clinics into intervention and control arms of the study did not take place until after baseline data were collected.

For each of the targeted cancer-screening tests, the date the procedure was completed was recorded to determine whether the patient was up-to-date on screening. We defined being up-to-date as having completed the targeted screening test within either the 12 months before the audited visit or within the 3 months after the audited visit. The use of a grace period has been applied in other studies ${ }^{37,55,56,59-61}$ and allows sufficient time for screening tests that were recommended at an audited visit to have been completed by the patient.

Chart abstracters used a standardized method and instrument to abstract chart information and were trained by the project manager. Relevant clinical data were abstracted from all sections of the chart, including progress notes, laboratory reports, radiology reports, consultation letters, and hospital records. Before beginning data collection, interrater reliability for chart abstractors was assessed for the 3 cancer-screening tests by re-reviewing a sample of 30 charts and calculating the kappa statistic. The following values of kappa were obtained when assessing whether a patient was up-todate on cancer screening: Pap smear, $\kappa=1.00^{\text {; mam- }}$ mogram, $\kappa=1.00$; FOBT, and $\kappa=0.91$.

Our statistical analyses focused on 3 primary outcomes. We assessed whether the patient was up-to-date on one or more of the following cancer screening tests: mammogram, Pap smear, or FOBT. Women who had a personal history of breast cancer were excluded from our analysis of mammograms. Women with a personal history of cervical cancer or those who had had a hysterectomy were excluded from our analysis of Pap smear screening. Patients with a personal history of colon cancer and those who had received a colonoscopy or double-contrast barium enema in the previous 10 years were excluded from the analysis of FOBT.

The final data set consisted of the combined abstracted records from the 2 independent samples collected at baseline and at 12 months postintervention. We adjusted simultaneously for potential confounders with the method of generalized linear models using PROC GENMOD in SAS (SAS Version 8, SAS Institute Inc, Cary, NC). The following variables were included in regression models: age, sex (if appropriate), race-ethnicity, marital status, smoking status, health insurance, comorbidity (using the Charlson Comorbidity Index ${ }^{62,63}$ ), number of chronic illnesses, number of prescribed medi- cations, number of health care visits in the previous year, clinic attended, primary language spoken, family history of targeted cancers, and for women the use of estrogen replacement therapy and history of benign breast disease.

Indicator variables were also created for clinic type (control vs intervention), and for survey year (baseline, postintervention 12-month follow-up). We also included an interaction term for the 2 variables of clinic type and survey year. The interaction term estimates the effect of the intervention while controlling for any baseline screening differences and secular trends in screening rates, and adjusting for other covariates. Because of the clustered nature of the data, with patients attending the same clinic and some patients being sampled by chance in both baseline and follow-up samples, we obtained parameter estimates and $95 \%$ confidence intervals using the method of generalized estimating equations. ${ }^{64,65}$

To calculate attributable numbers, we first estimated the relative risks from odds ratios using the formula by Zhang and Yu. ${ }^{66}$ We then calculated attributable fractions for each screening test and used these to estimate the number of cancer-screening tests obtained among subjects that could be attributed to the Cancer SOS intervention. ${ }^{67}$ We also assessed in preliminary fashion whether the Cancer SOS intervention is cost-effective as well as efficacious (for details, see Appendix 2, which is available online only at http://www.annfammed.org/cgi/content/full/2/4/294/ DC1). This assessment involved estimating the costs of carrying out the intervention per patient and per screening test, and determining marginal costs $(\Delta \mathrm{C})$ and marginal effectiveness $(\Delta \mathrm{E})$ of the intervention. The incremental cost-effectiveness $\Delta \mathrm{C} / \Delta \mathrm{E}$ of the Cancer SOS intervention was then compared, where possible, with comparable interventions reported in the published literature. This study was reviewed and approved by the University of South Florida Institutional Review Board, which waived the requirement for informed consent of individual patients.

\section{RESULTS}

Table 1 summarizes the clinical characteristics of patients attending control and intervention clinics. Screening rates 12 months after the intervention had been implemented were as follows: for Pap smears, intervention $62.4 \%$, control $48.2 \%$; for mammograms, intervention $75.7 \%$, control $71.1 \%$; and for fecal occult blood testing, intervention $40.1 \%$, control $11.9 \%$. During the 12 month follow-up period, screening rates in intervention clinics increased relative to screening rates in control clinics by the following amounts: FOBT, $14.4 \%$; mammograms, 9.1\%; and Pap smears, 9.9\%. We also assessed the total number of screening tests obtained among women who were eligible for the 3 cancer-screening 


\begin{tabular}{|c|c|c|c|c|c|}
\hline \multirow[b]{2}{*}{ Clinical Characteristics } & \multicolumn{2}{|c|}{ Control } & \multicolumn{2}{|c|}{ Intervention } & \multirow[b]{2}{*}{$P$ Value } \\
\hline & No. & $\%$ & No. & $\%$ & \\
\hline Group & 596 & 49.8 & 600 & 50.2 & \\
\hline Sex & & & & & .88 \\
\hline Male & 129 & 21.6 & 132 & 22.0 & \\
\hline Female & 467 & 78.4 & 468 & 78.0 & \\
\hline Age, years & & & & & .38 \\
\hline $50-56$ & 212 & 35.6 & 232 & 38.7 & \\
\hline $57-63$ & 196 & 32.9 & 199 & 33.1 & \\
\hline $64-75$ & 188 & 31.5 & 169 & 28.3 & \\
\hline Race-ethnicity & & & & & .0009 \\
\hline African American & 144 & 24.2 & 204 & 34.0 & \\
\hline White & 307 & 51.5 & 272 & 45.3 & \\
\hline Hispanic & 145 & 24.3 & 124 & 20.7 & \\
\hline Marital status & & & & & .003 \\
\hline Married & 142 & 23.8 & 189 & 31.5 & \\
\hline Unmarried & 454 & 76.2 & 411 & 68.5 & \\
\hline Primary language & & & & & .23 \\
\hline English & 464 & 77.8 & 484 & 80.7 & \\
\hline Non-English (Spanish) & 132 & 22.2 & 116 & 19.3 & \\
\hline Health insurance & & & & & .48 \\
\hline County program & 354 & 59.4 & 346 & 57.7 & \\
\hline Medicaid & 83 & 13.9 & 101 & 16.8 & \\
\hline Medicare & 122 & 20.5 & 112 & 18.7 & \\
\hline Other & 37 & 06.2 & 41 & 06.8 & \\
\hline Smoking status & & & & & .61 \\
\hline Smoker & 163 & 27.4 & 172 & 28.7 & \\
\hline Nonsmoker & 433 & 72.6 & 428 & 71.3 & \\
\hline Health maintenance visit in past year & & & & & .16 \\
\hline Yes & 329 & 55.2 & 307 & 48.8 & \\
\hline No & 267 & 44.8 & 293 & 51.2 & \\
\hline Charlson comorbidity score & & & & & $<.0001$ \\
\hline 0 & 249 & 41.8 & 175 & 29.2 & \\
\hline 1 & 129 & 21.7 & 146 & 24.3 & \\
\hline 2 & 120 & 20.1 & 156 & 26.0 & \\
\hline$>3$ & 98 & 16.4 & 123 & 20.5 & \\
\hline Chronic illnesses & & & & & $<.0001$ \\
\hline $0-4$ & 214 & 35.9 & 127 & 21.2 & \\
\hline $5-7$ & 233 & 39.1 & 235 & 39.2 & \\
\hline$>8$ & 149 & 25.0 & 238 & 39.6 & \\
\hline Medications prescribed & & & & & $<.0001$ \\
\hline $0-5$ & 272 & 45.6 & 110 & 18.3 & \\
\hline $6-8$ & 182 & 30.5 & 153 & 25.5 & \\
\hline$>9$ & 142 & 23.8 & 337 & 56.2 & \\
\hline Health care visits in past year & & & & & $<.0001$ \\
\hline $0-4$ & 213 & 35.7 & 150 & 25.0 & \\
\hline $5-7$ & 185 & 31.0 & 185 & 30.8 & \\
\hline$>8$ & 198 & 33.2 & 265 & 44.2 & \\
\hline Papanicolaou smear in past year* & & & & & .33 \\
\hline Yes & 148 & 57.6 & 151 & 61.9 & \\
\hline No & 109 & 42.4 & 93 & 38.1 & \\
\hline Mammogram in past year* & & & & & .13 \\
\hline Yes & 337 & 75.9 & 325 & 71.4 & \\
\hline No & 107 & 24.1 & 130 & 28.6 & \\
\hline Fecal occult blood test in past year* & & & & & $<.0001$ \\
\hline Yes & 109 & 22.1 & 180 & 35.9 & \\
\hline No & 384 & 77.9 & 321 & 64.1 & \\
\hline
\end{tabular}

tests. At the 12 month follow-up, women in control clinics had received on average 1.25 cancer-screening tests compared with an average of 1.71 tests for women in intervention clinics (Wilcoxon rank sum $=7.94, P<.0001)$.

Multivariate analysis was used to assess the effectiveness of the intervention by determining the odds ratio for the interaction term previously described (Table 2). (Appendix 3, available online only at http://www.annfammed. org/cgi/content/full/2/4/294/DC1 describes other clinical predictors

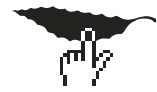
of screening). The intervention more than doubled the odds of FOBT screening, increased the odds of mammograms more than $60 \%$, and increased the odds of screening Pap smears more than 50\% (a finding that did not reach statistical significance, however). The impact of the intervention was also assessed in absolute terms. Among the intervention patients that were assessed at follow-up, the intervention resulted in 27 additional Pap smears among the 282 women eligible for screening, 33 additional mammograms among the 481 women eligible for screening, and 94 additional FOBTs among the 496 men and women who were eligible for screening. The corresponding numbers needed to treat (NNT) are as follows; Pap smear NNT $=10.4$, mammograms NNT = 14.6, and FOBT NNT = 5.3.

On a per-patient basis, we estimate that the real costs of Cancer SOS are $\$ 5.39$. When the expected cost per patient is allocated across the 3 screening tests, we find that the costs for mammography, Pap smears, and FOBT are $\$ 2.55, \$ 1.96$, and $\$ 2.96$, respectively. When these per test costs are divided by the incremental effectiveness of Cancer SOS in respect to each test, we find $\Delta \mathrm{C} / \Delta \mathrm{E}$ ratios of $\$ 55, \$ 14$, and $\$ 11$ for mammography, Pap smears, and FOBT, respectively, which compare favorably with other screening interventions reported in the literature (see Appendix 2 for further details).

\section{DISCUSSION}

The Cancer SOS intervention successfully increased cancer screening in clin- 


\begin{tabular}{|c|c|c|c|c|}
\hline Screening Test & Number & $\begin{array}{l}\text { Odds } \\
\text { Ratio }\end{array}$ & $95 \% \mathrm{Cl}$ & $P$ Value \\
\hline Papanicolaou smears & 1,057 & 1.57 & $0.92-2.64$ & .096 \\
\hline Mammograms & 1,832 & 1.62 & $1.07-9.78$ & .023 \\
\hline Fecal occult blood test & 1,989 & 2.56 & $1.65-4.01$ & $<.0001$ \\
\hline
\end{tabular}

effectiveness ratios for interventions designed to increase the number of women undergoing screening mammography. More particularly, we found that the incremental cost-effectiveness ratio of Cancer SOS appeared to be lower than that reported by 9 of the 12 comparable studies found in our search of the US literature. ${ }^{71-83}$

Finally, the ability of successful interventions to diffuse from experimental settings into usual practice settings is largely unproved.

ics serving primarily disadvantaged populations. After 12 months of follow-up, the odds of screening with mammography and FOBT both increased significantly, with a trend toward increased provision of Pap smears as well. In total, 154 additional cancer-screening tests could be attributed to the intervention among the 628 patients sampled at follow-up. Similar reminder systems have been tested in the past and are among the more successful strategies to promote cancer screening in primary care practices. ${ }^{56-58}$ The novelty of our intervention results from its low cost, no need for computers, and involvement of the patient in the screening process.

The magnitude of effects of the Cancer SOS intervention was generally similar to those reported in systematic reviews. ${ }^{26,29}$ It is difficult to compare strictly the magnitude of effects of the Cancer SOS intervention with other studies because most interventions are uniquely structured, and baseline screening rates vary considerably among studies. Among the 3 targeted screening tests, the magnitude of effect was clearly the greatest for FOBT. Screening rates for FOBT lag considerably behind those of Pap smears and mammograms, so there is much more room for improvement. Nationwide rates of colorectal cancer screening are among the lowest for recommended cancer-screening tests. ${ }^{68,69}$

There are several important questions concerning the viability of office systems as a general approach to increasing cancer-screening rates among disadvantaged populations. First is the durability of effects with time. Whereas many interventions increase cancer-screening behaviors for the short term, few have assessed durability of long-term effects. ${ }^{60,70}$ Although the Cancer SOS intervention was successful for a 12-month period, it will be important to determine whether effects can be sustained, a question that will be addressed in a future study assessing outcomes at 24 months' follow-up.

A second important factor is whether intervention strategies are cost-effective. Even though a more detailed analysis is planned, preliminary analysis suggests the Cancer SOS has reasonable cost-effectiveness. The least favorable cost-effectiveness ratio was observed for screening mammography, attributable mostly to the lower $\Delta \mathrm{E}$ term for that test compared with Pap smears and FOBT. But even this ratio compares favorably to published cost-
To promote generalizability of our office systems approach, we attempted to utilize low-cost strategies and relied on personnel within the clinic as much as possible to carry out intervention tasks. It is also important to acknowledge that the Cancer SOS intervention targeted only 3 preventive services. Whether the intervention could be structured to improve preventive care more comprehensively is uncertain but would appear to be unlikely. The structure of Cancer SOS is more apt to be of value for providers who wish to improve a select number of preventive services.

We can also learn from situations in which office systems approaches have been less effective. First, there seems to be less success when clinic leadership is unstable. ${ }^{59,84}$ Dietrich and colleagues ${ }^{59}$ believed that office systems approaches face more obstacles in larger practices than in smaller practices, although their studies were unable to assess this issue rigorously. Studies have also reported less success when office systems interventions are applied to more representative samples of clinics as opposed to those samples that are recruited and presumably more highly motivated. ${ }^{59,84}$ While not rigorously assessed in our study, all these observations ring true with our work with the Cancer SOS project. As such, we believe that interventions such as Cancer SOS will be most successful in clinics with stable leadership and at least minimal motivation to improve cancer screening.

This study has other limitations that should be considered. For simplicity we targeted a uniform age-group and uniform screening intervals (1 year) for 3 selected tests, and it is not known how the system would work if structured differently. Although our analysis was able to control for clustering that occurred at the level of the clinic, we did not collect detailed information on provider visits and were therefore unable to control for any clustering that may have occurred at the level of the individual physician. Finally, the Cancer SOS contained several components (the checklists, feedback of screening rates to clinic staff, etc), and our study is unable to assess the relative contribution of individual components.

In conclusion, we found that the Cancer SOS intervention significantly increased rates of cancer screening among primary care clinics serving disadvantaged populations. This finding suggests that office systems 
approaches may be one strategy to increasing cancer screening among underserved populations who are at greater risk of late-stage disease and poor cancer outcomes. Further study on the sustainability, cost-effectiveness, and limitations of this approach are warranted.

To read or post commentaries in response to this article, see it online at http://www.annfammed.org/cgi/content/full/2/4/294.

Key words: Mass screening; mammography; vaginal smears; occult blood; breast neoplasms; colorectal neoplasms; community health centers; primary health care

Submitted June 11, 2003; submitted, revised, September 12, 2004; accepted October 13, 2004.

Funding support: This research was supported by National Cancer Institute grant R01 CA77282.

\section{References}

1. Miller B, Ries L, Hankey B, Kosary C, Edwards B. Cancer Statistics Review: 1973-1989. Washington, DC: National Cancer Institute; 1992:9. NIH Publication 92-278.

2. Mandelblatt J, Andrews H, Kao R, Wallace R, Kerner J. The late-stage diagnosis of colorectal cancer: demographic and socioeconomic factors. Am J Public Health. 1996;86:1794-1797.

3. Ndubuisi SC, Kofie VY, Andoh JY, Schwartz EM. Black-white differences in the stage at presentation of prostate cancer in the District of Columbia. Urology. 1995;46:71-77.

4. Roetzheim RG, Pal N, Tennant C, et al. Effects of health insurance and race on early detection of cancer. J Natl Cancer Inst. 1999;91:1409-1415.

5. Roetzheim RG, Gonzalez EC, Ferrante JM, Pal N, Van Durme DJ, Krischer JP. Effects of health insurance and race on breast carcinoma treatments and outcomes. Cancer. 2000;89:2202-2213.

6. Roetzheim RG, Pal N, Gonzalez EC, Ferrante JM, Van Durme DJ, Krischer JP. Effects of health insurance and race on colorectal cancer treatments and outcomes. Am J Public Health. 2000;90:1746-1754.

7. Richardson JL, Langholz B, Bernstein L, Burciaga C, Danley K, Ross RK. Stage and delay in breast cancer diagnosis by race, socioeconomic status, age and year. Br J Cancer. 1992;65:922-926.

8. Farley TA, Flannery JT. Late-stage diagnosis of breast cancer in women of lower socioeconomic status: public health implications. Am J Public Health. 1989;79:1508-1512.

9. Wells BL, Horm JW. Stage at diagnosis in breast cancer: race and socioeconomic factors. Am J Public Health. 1992;82:1383-1385.

10. Bassett M, Krieger N. Social class and black-white differences in breast cancer survival. Am J Public Health. 1986;76:1400-1403.

11. Mandelblatt J, Andrews H, Kerner J, Zauber A, Burnett W. Determinants of late stage diagnosis of breast and cervical cancer: the impact of age, race, social class, and hospital type. Am J Public Health. 1991;81:646-649.

12. Hunter C, Redmond C, Chen V, et al. Breast cancer: factors associated with stage at diagnosis in black and white women. J Natl Cancer Inst. 1993;85:1129-1137.

13. Eley JW, Hill HA, Chen VW, et al. Racial differences in survival from breast cancer. results of the National Cancer Institute Black/White Cancer Survival Study. JAMA. 1994;272:947-954.

14. Ayanian J, Kohler B, Abe T, Epstein A. The relation between health insurance coverage and clinical outcomes among women with breast cancer. N Engl J Med. 1993;329:326-331.

15. Stein J, Fox S. Language preference as an indicator of mammography use among Hispanic women. J Natl Cancer Inst. 1990;82:1715-1716.

16. Calle E, Flanders W, Thun M, Martin L. Demographic predictors of mammography and Pap smear screening in US women. Am J Public Health. 1993;83:53-60.
17. Anderson L, May D. Has the use of cervical, breast, and colorectal cancer screening increased in the United States? Am J Public Health. 1995;85:840-842.

18. Lee J, Vogel V. Who uses screening mammography regularly? Cancer Epidemiol, Biomarkers, Prev. 1995;4:901-906.

19. Harlan L, Bernstein A, Kessler L. Cervical cancer screening: who is not screened and why? Am J Public Health. 1991;81:885-891.

20. Burns $\mathrm{R}, \mathrm{McC}$ arthy $E$, Freund $\mathrm{K}$, et al. Black women receive less mammography even with similar primary care. Ann Intern Med. 1996;125:173-182.

21. National Cancer Institute Breast Cancer Screening Consortium. Screening mammography: a missed clinical opportunity? JAMA. 1990;264:54-58.

22. The National Cancer Institute Screening Consortium for Underserved Women. Breast and cervical cancer screening among underserved women. Baseline survey results from six states. Arch Fam Med. 1995;4:617-624.

23. Hayward R, Shapiro M, Freeman H, Corey C. Who gets screened for cervical and breast cancer? Results from a new national survey. Arch Intern Med. 1988:1177-1181.

24. Breen N, Kessler L. Changes in the use of screening mammography: evidence from the 1987 and 1990 National Health Interview Surveys. Am J Public Health. 1994;84:62-67.

25. McPhee S, Detmer W. Office-based interventions to improve delivery of cancer prevention services by primary care physicians. Cancer. 1993;72(3 Suppl):1100-1112.

26. Mandelblatt J, Kanelsky P. Effectiveness of interventions to enhance physician screening for breast cancer. J Fam Pract. 1995;40:162-171.

27. Snell J, Buck E. Increasing cancer screening: a meta-analysis. Prev Med. 1996;25:702-707

28. Hulscher $M$, Wensing $M$, Grol $R$, van der Weijden $T$, van Weel $C$. Interventions to improve the delivery of preventive services in primary care. Am J Public Health. 1999;89:737-746.

29. Stone EG, Morton SC, Hulscher ME, et al. Interventions that increase use of adult immunization and cancer screening services: a metaanalysis. Ann of Intern Med. 2002;136:641-651.

30. McDonald C, Hui S, Smith D, et al. Reminders to physicians from an introspective computer medical record: a two-year randomized trial. Ann Intern Med. 1984;100:130-138.

31. Tierney W, Hui S, McDonald C. Delayed feedback of physician performance vs. immediate reminders to perform preventive care. Med Care. 1986;24:659-666

32. McPhee S, Bird J, Jenkins C, Fordham D. Promoting cancer screening: a randomized, controlled trial of three interventions. Arch Intern Med. 1989; 149:1866-1872

33. Turner B, Day S, Borenstein B. A controlled trial to improve delivery of preventive care: physician or patient reminders? J Gen Intern Med. 1989;4:403-409.

34. Chambers C, Balaban D, Carlson B, Ungemack J, Grasberger D. Microcomputer-generated reminders: improving the compliance of primary care physicians with mammography screening guidelines. J Fam Pract. 1989;29:273-280.

35. McDowell I, Newell C, Rosser N. Computerized reminders to encourage cervical screening in family practice. J Fam Pract. 1989;28:420-424.

36. Chodroff C. Cancer Screening and immunization quality assurance using a personal computer. QRB Qual Rev Bull. 1990;16:279-287.

37. Ornstein S, Garr D, Jenkins R, Rust P, Arnon A. Computer-generated physician and patient reminders: tools to improve population adherence to selected preventive services. J Fam Pract. 1991;32:82-90.

38. McPhee S, Bird J, Fordham D, Rodnick J, Osborn E. Promoting cancer prevention activities by primary care physicians. JAMA. 1991;266:538-544.

39. Becker D, Gomez E, Kaiser D, Yoshihasi A, Hodge R. Improving preventive care at a medical clinic: how can the patient help. Am J Prev Med. 1989;5:353-359. 
40. Litzelman D, Dittus R, Miller M, Tierney W. Requiring physicians to respond to computerized reminders improves their compliance with preventive care protocols. J Gen Intern Med. 1993;8:311-317.

41. Burack RC, Gimotty PA. Promoting screening mammography in innercity settings. the sustained effectiveness of computerized reminders in a randomized controlled trial. Med Care. 1997;35:921-931.

42. Burack RC, Gimotty PA, George J, Simon MS, Dews P, Moncrease $A$. The effect of patient and physician reminders on use of screening mammography in a health maintenance organization. Results of a randomized controlled trial. Cancer. 1996;78:1708-1721.

43. Frame PS, Zimmer JG, Werth PL, Hall WJ, Eberly SW. Computerbased vs manual health maintenance tracking. A controlled trial. Arch Fam Med. 1994;3:581-588.

44. Williams R, Boles M, Johnson R. A patient-initiated system for preventive health care: a randomized trial in community-based primary care practices. Arch Fam Med. 1998;7:338-345.

45. Paskett ED, McMahon K, Tatum C, et al. Clinic-based interventions to promote breast and cervical cancer screening. Prev Med. 1998;27:120-128.

46. Hermens RP, Hak E, Hulscher ME, Braspenning JC, Grol RP. Adherence to guidelines on cervical cancer screening in general practice: programme elements of successful implementation. Br J Gen Pract. 2001;51:897-903.

47. Davidson R, Fletcher S, Retchin S, Duh S. A nurse-initiated reminder system for the periodic health examination: implementation and evaluation. Arch Intern Med. 1984;144:2167-170.

48. Foley E, D'Amico F, Merenstein J. Improving mammography recommendation: a nurse-initiated intervention. J Am Board Fam Pract. 1990;3:87-92.

49. Belcher D. Implementing preventive services: success and failure in an outpatient trial. Arch Intern Med. 1990;150:2533-2541

50. Taylor V, Thompson B, Lessler D, et al. A clinic-based mammography intervention targeting inner-city women. J Gen Intern Med. 1999;14:104-111.

51. Hiatt RA, Pasick RJ, Stewart S, et al. Community-based cancer screening for underserved women: design and baseline findings from the Breast and Cervical Cancer Intervention Study. Prev Med. 2001;33:190-203.

52. Coleman EA, Lord J, Heard J, et al. The Delta project: increasing breast cancer screening among rural minority and older women by targeting rural healthcare providers. Oncol Nurs Forum. 2003;30:669-677.

53. Champion VL, Skinner CS, Menon U, Seshadri R, Anzalone DC, Rawl SM. Comparisons of tailored mammography interventions at two months postintervention. Ann Behav Med. 2002;24:211-218.

54. Margolis KL, Lurie N, McGovern PG, Tyrrell M, Slater JS. Increasing breast and cervical cancer screening in low-income women. J Gen Intern Med. 1998;13:515-521.

55. Dickey L, Petitti D. A patient-held minirecord to promote adult preventive care. J Fam Pract. 1992;34:457-463.

56. Dietrich A, O'Connor G, Keller A. Cancer: improving early detection and prevention. Br Med J. 1992;304:687-691.

57. Preston JA, Scinto JD, Grady JN, Schulz AF, Petrillo MK. The effect of a multifaceted physician office-based intervention on older women's mammography use. J Am Geriatr Soc. 2000;48:1-7.

58. Manfredi C, Czaja R, Freels S, Trubitt M, Warnecke R, Lacey L. Prescribe for health. Improving cancer screening in physician practices serving low-income and minority populations.[comment]. Arch Fam Med. 1998;7:329-337.

59. Dietrich A, Tobin J, Sox C, et al. Cancer early-detection services in community health centers for the underserved: a randomized controlled trial. Arch Fam Med. 1998;7:320-327.

60. Dietrich A, Sox C, Tosteson T, Woodruff C. Durability of improved physician early detection of cancer after conclusion of intervention support. Cancer Epidemiol Biomarkers Prev. 1994;3:335-340.

61. Fletcher S, Harris R, Gonzalez J, et al. Increasing mammography utilization: a controlled study. J Natl Cancer Inst. 1993;85:112-120.
62. Charlson M, Pompei P, Ales K, Mackenzie C. A new method of classifying prognostic comorbidity in longitudinal studies: development and validation. J Chron Dis. 1987;40:373-383.

63. Charlson M, Szatrowski T, Peterson J, Gold J. Validation of a combined comorbidity index. J Clin Epidemiol. 1994;47:1245-1251.

64. Liang K, Zeger S. Regression analysis for correlated data. Ann Rev Public Health. 1993;14:43-68.

65. Liang K, Zeger S. Longitudinal data analysis using generalized linear models. Biometrika. 1986;73:13-22.

66. Zhang J, Yu K. What's the relative risk? A method of correcting the odds ratio in cohort studies of common outcomes. JAMA. 1998;280:1690-1691.

67. Kleinbaum D, Kupper L, Morgenstern H. Epidemiologic Research: Principles and Quantitative Methods. Belmont, Calif: Lifetime Learning Publication; 1982.

68. Trends in screening for colorectal cancer--United States, 1997 and 1999. MMWR - Morbidity \& Mortality Weekly Report. 2001;50:162-166.

69. Shapiro JA, Seeff LC, Nadel MR. Colorectal cancer-screening tests and associated health behaviors. Am J Prev Med. 2001;21:132-137.

70. Cooley KA, Frame PS, Eberly SW. After the grant runs out. Longterm provider health maintenance compliance using a computerbased tracking system. Arch Fam Med. 1999;8:13-17.

71. Anderson M, Hager M, Urban N. Analysis of the cost-effectiveness of mammography promotion by volunteers in rural communities. Health Educ Behav. 2002;29:755-770.

72. Bird J, McPhee S, Jenkins C, Fordham D. Three strategies to promote cancer screening: how feasible is wide-scale implementation? Med Care. 1990;28:1005-1012.

73. Costanza ME, Stoddard AM, Luckmann R, White MJ, Spitz Avrunin J, Clemow L. Promoting mammography: results of a randomized trial of telephone counseling and a medical practice intervention. Am J Prev Med. 2000;19:39-46.

74. Crane LA, Leakey TA, Ehrsam G, Rimer BK, Warnecke RB. Effectiveness and cost-effectiveness of multiple outcalls to promote mammog raphy among low-income women. Cancer Epidemiol Biomarkers Prev. 2000;9:923-931.

75. Fishman P, Taplin S, Meyer D, Barlow W. Cost-effectiveness of strategies to enhance mammography use. Eff Clin Pract. 2000;5:213-220.

76. Lantz P, Stencil D, Lippert M, Jaros L, Eaker E. Implementation issues and costs associated with a proven strategy for increasing breast and cervical cancer screening among low-income women. J Public Health Manag Pract. 1996;2:54-59.

77. Mohler P. Enhancing compliance with screening mammography recommendations: a clinical trial in a primary care office. Fam Med. 1995;27:117-121.

78. Saywell R, Champion V, Skinner C, McQuillen D, Martin D, Maraj M. Cost-effectiveness comparison of five interventions to increase mammography screening. Prev Med. 1999;29:374-382.

79. Saywell R, Champion V, Zollinger $T$, et al. The cost-effectiveness of 5 interventions to increase mammography adherence on a managed care population. Am J Manag Care. 2003;9:33-44.

80. Stockdale SE, Keeler E, Duan N, Derose KP, Fox SA. Costs and costeffectiveness of a church-based intervention to promote mammography screening. Health Serv Res. 2000;35:1037-1057.

81. Thompson B, Thompson LA, Andersen MR, Hager S, Taylor V, Urban $\mathrm{N}$. Costs and cost-effectiveness of a clinical intervention to increase mammography utilization in an inner city public health hospital. Prev Med. 2002;35:87-96

82. Van Harrison $\mathrm{R}$, Janz $\mathrm{N}$, Wolfe $\mathrm{R}$, et al. Personalized targeted mailing increases mammography among long-term noncompliant Medicare beneficiaries: a randomized trial. Med Care. 2003;41:375-385.

83. Weber B, Reilly B. Enhancing mammography use in the inner city, a randomized trial of intensive case management. Arch Intern Med. 1997; 157:2345-2349.

84. Kinsinger LS, Harris R, Qaqish B, Strecher V, Kaluzny A. Using an office system intervention to increase breast cancer screening. J Gen Intern Med. 1998;13:507-514 